\title{
Posterior Affricate in Mee and Consonant-Vowel Place Interactions
}

\author{
Peter Staroverov and Sören Tebay \\ Wayne State University and Universität Leipzig
}

\section{Introduction}

Velar laterals are a rare class of sounds that involve posterior closure and lateral release (Ladefoged et al., 1977; Blevins, 1994; François, 2010). This article documents the realization of a velar lateral in Mee (a.k.a. Ekari, Ekagi, Kapauku) - a Paniai Lakes Nuclear Trans New Guinea language spoken in the Indonesian part of Papua New Guinea (Doble, 1962; Steltenpool, 1969; Doble, 1987; Hyman \& Kobepa, 2013). In the speech of our consultants, the velar lateral exhibits a previously undocumented pattern of allophony: it appears as expected $\left[\mathrm{g}^{\mathrm{L}}\right]$ before front vowels, but is realized with uvular closure and fricative release, i.e. $\left[\mathrm{G}^{\mathrm{B}}\right]$ before back vowels. Perhaps owing to the rare occurrence of velar laterals, there are few phonetically detailed descriptions of these sounds (Ladefoged et al., 1977; Steed \& Hardie, 2004; François, 2010, 2011), and to our knowledge this is the first report of velar lateral allophony based on vowel frontness, and one of the few reports of voiced uvular affricates (cf. Chirkova \& Chen (2013) on a marginal sound in Xumi).

Unlike velar laterals in other languages, the Mee sound always has a discernible closure phase, and our acoustic data suggest that vowel frontness has an effect on both the closure and release of this sound. This pattern is best described by assuming that the major place of articulation of Mee posterior consonant alternates with vowel frontness. This finding thus presents a challenge to the idea that only V-place or secondary articulation features are involved in consonant-vowel interactions (Ní Chiosáin \& Padgett, 1993; Padgett, 2011).

Building on the existing analyses of other languages where velar/uvular consonant quality correlates with vowel frontness or tenseness (Svantesson et al., 2005; Becker, 2016), we argue that velar vs. uvular distinction can be analyzed with inherently vocalic features such as [back] or [ATR], and that there are AGREE constraints promoting feature sharing between the consonant release and a following vowel, as well as between consonant closure and release. Thus although we do not have a constraint requiring $\mathrm{C}-\mathrm{V}$ agreement in major place, this effect is derived from activity of two narrow-scope constraints in a pattern similar to rule telescoping (Kenstowicz \& Kisseberth, 1977).

\section{Data and method}

2.1 Background on Mee Mee (iso: ekg) is spoken in the Paniai region of the central highlands of West Irian, in the valleys surrounding and to the north of Paniai and Tigi lakes (Steltenpool, 1969; Doble, 1987). Mee is closely related to Wodani and Moni (Larson \& Larson, 1972) and possibly to Auye (Moxness, 2011; Tebay, 2018b). Our data come from fieldwork with two male speakers of Mee, the participant details are presented in section 2.3.

The Mee consonant inventory is presented in (1). The velar lateral will be represented as $/ \mathrm{g}^{\mathrm{L}} /$ in what follows. In section 2.2, we present several arguments supporting our description.

\footnotetext{
* We are very grateful to our Mee consultants for sharing their language with us. Our fieldwork would not be possible without comments, support and discussion by Martina Martinović, Barbara Stiebels, Elena Pyatigorskaya, and the participants in the 2016 Field Methods class at Leipzig University. For helpful comments on earlier versions of this work we thank Edward Flemming, Marc Garellek, Martha Ratliff, Sharon Rose, and the participants at AMP 2018. Financial support came from DFG (GRK 2011); Leipzig University; Wayne State University. All errors are our own.
} 
(1)

\begin{tabular}{l|c|c|c} 
Mee consonant inventory \\
& Labial & Coronal & Dorsal \\
\hline Stops & $\mathrm{p} \mathrm{b}$ & $\mathrm{t} \mathrm{d}$ & $\mathrm{k} \mathrm{g}^{\mathrm{L}} / \mathrm{G}^{\mathrm{B}}$ \\
Nasals & $\mathrm{m}$ & $\mathrm{n}$ & \\
Glides & $\mathrm{w}$ & $\mathrm{j}$ &
\end{tabular}

Mee vowels and diphthongs are listed in (2). /a/ patterns with back / $\mathrm{u}$ o/ in conditioning velar lateral allophony.

\begin{tabular}{|c|c|c|}
\hline \multicolumn{3}{|c|}{ Mee vowel inventory } \\
\hline Mc & ngs & Diphthongs \\
\hline i i: & $\mathrm{u} u \mathrm{t}$ & ei, ai, eu, au, ou \\
\hline e e: & O O: & \\
\hline
\end{tabular}

Mee also exhibits some interesting tonal alternations, as analyzed by Hyman \& Kobepa (2013) and Worbs (2016). Since the Mee tonal system has been described extensively elsewhere, we will not focus on tone in this paper. Mee only allows $\mathrm{CV}(\mathrm{V})$ syllables, and employs a variety of strategies to resolve potential hiatus (Tebay, 2018a).

2.2 Mee velar lateral This section introduces the Mee velar lateral, and addresses its phonological status. Across languages, velar laterals may pattern with stops, laterals, or affricates (François, 2010). We argue that Mee velar lateral should be treated as an underlying affricate for several reasons. On the one hand, this segment patterns with stops in many ways. It is consistently realized phonetically with a closure phase - in this respect it is different from the velar lateral in Mid-Waghi (Ladefoged et al., 1977). Out of the 313 tokens we recorded for the acoustic study, only four were realized without a clearly discernible closure phase. The Mee velar laterals also seems to derive historically from a stop. Evidence for this assumption comes from Moni, where the corresponding sound is described as a stop [ $\mathrm{k} / \mathrm{g}]$ in most contexts (Larson \& Larson, 1958). See Larson \& Larson (1972) on the relation between Mee, Wodani, and Moni and Tebay (2018b) for a list of cognate words. Finally, our consultants seem to associate $\left[g^{\mathrm{L}} \sim \mathrm{G}^{\mathrm{B}}\right]$ with other stops, as evidenced by their orthographic intuitions. While the consultants were not aware of a standardized orthography for Mee, they agreed that the velar lateral sound should be written with the $\langle\mathrm{g}>$ symbol, rather than $<\mathrm{l}>$ or $<\mathrm{r}>$.

Despite the fact that Mee velar lateral patterns with stops in many ways, there are reasons not to describe it simply as a voiced stop /g/. The realization of this sound involves a phonetically salient release which is distinct from that of plain stops, and our elicitations show that lateral or fricated release is not optional. Mee grammar must therefore somehow encode the fact that the posterior [-continuant] segment has a release distinct from maximal opening ( $\mathrm{A}_{\max }$ in Steriade (1993)). As discussed in detail in section 4, the presence of this release target does not immediately follow from any properties of the context, and such a release is not robustly present for any of the other Mee stops. ${ }^{1}$ The phonetic salience of the lateral/uvular release of $/ \mathrm{g}^{\mathrm{L}} /$ also manifests itself in loanword adaptations such as [tekoG $\left.{ }^{\mathrm{B}} \mathrm{a}\right]$ 'school' from Indonesian $<$ sekolah $>$ [səkola].

We propose to represent the Mee velar lateral as an underlying affricate $/ g^{\mathrm{L}} /$. Anticipating our analysis in section 4 , we derive the uvular allophone based on the assumption that uvular laterals are impossible. Treating the velar lateral as an affricate on the one hand allows for a natural class of Mee [-continuant] obstruents, but on the other hand captures the fact that only the posterior voiced obstruent has a lateral release.

$/ \mathrm{g}^{\mathrm{L}} /$ realization is the main topic of our acoustic study, and our results can be summarized as follows. $/ \mathrm{g}^{\mathrm{L}} /$ is realized phonetically with dorsal closure and lateral release before front vowels and corresponding diphthongs /ei eu/ (3-a). Before back vowels /a o u/ and corresponding diphthongs /ai au ou/, Mee $/ \mathrm{g}^{\mathrm{L}} / \mathrm{is}$ realized with uvular closure and fricative release, transcribed $\left[\mathrm{G}^{\mathrm{B}}\right](3-\mathrm{b})$.

Examples of Mee posterior lateral

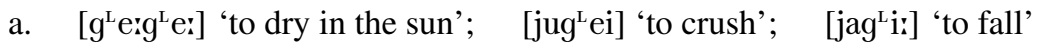

b. [G ${ }^{\mathrm{B}}$ a:ti $]$ 'ten'; $\left[\mathrm{daG}^{\mathrm{B}} \mathrm{u}\right]$ 'room'; $\left[\mathrm{eG}^{\mathrm{B}} \mathrm{Ou}\right]$ 'to pull'

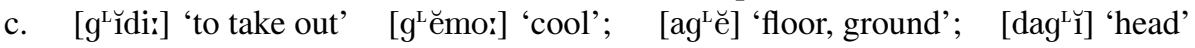

\footnotetext{
1 In the speech of consultant S2 the coronal stop occasionally does sound laterally released, but the presence of lateral release is much less common here: many variants without a lateral release are also recorded.
} 

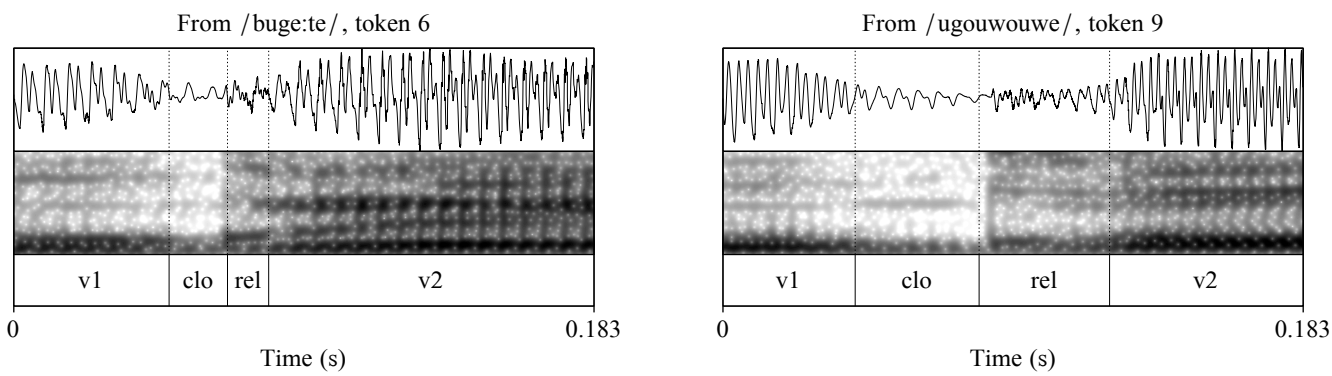

Figure 1: Waveform and spectrogram of $/ g^{\mathrm{L}} /$ with periodic release before a front vowel (left) and a back vowel (right)
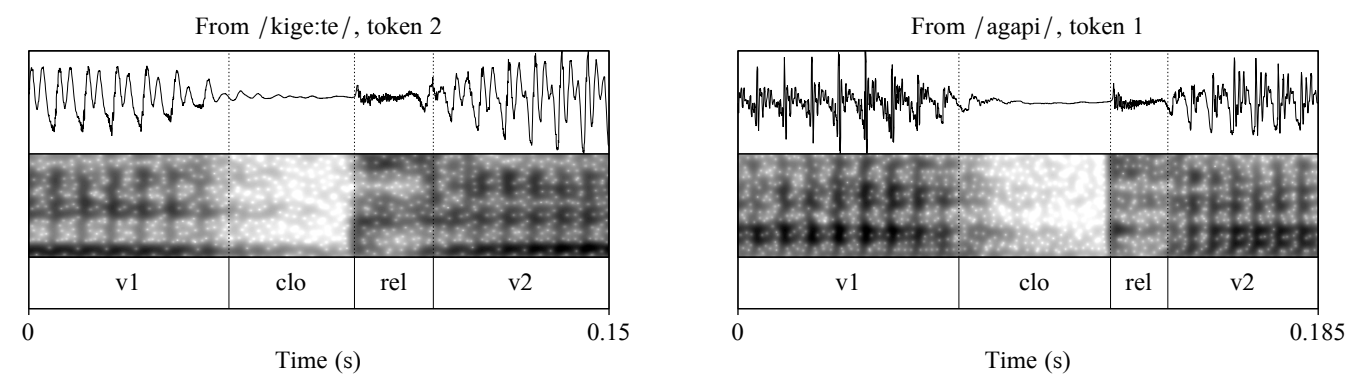

Figure 2: Waveform and spectrogram of $/ \mathrm{g}^{\mathrm{L}} /$ with aperiodic release before a front vowel (left) and a back vowel (right)

Short /i e/ are reduced and highly lateralized after $\left[g^{\mathrm{L}}\right]$, transcribed with a breve sign in (3) and in what follows. This reduction process is more pronounced in connected speech and in non-first syllables. The contrast between /gi/ and /ge/ in non-first syllables, as in the last two words in (3-c) appears hardly perceptible, although our consultants do distinguish such words. Moreover, short word-final /i/ vs. /e/ serve as distinct subject agreement markers in some tenses, including after $/ \mathrm{g} /$, where $/-\mathrm{i} /$ corresponds to $1 \mathrm{pl}$. and $2 \mathrm{sg}$, and /-e/ - to masculine 3sg. (Doble, 1987). The cues for differentiating $\left[g^{\mathrm{L} \breve{1}}\right]$ vs. [ $\left.g^{\mathrm{L} \breve{e}}\right]$ sequences in Mee remain to be investigated.

Some typical waveforms and spectrograms illustrating Mee velar lateral realization are presented in Figures $1-2$. These illustrations are taken from tokens of words with $/ \mathrm{g}^{\mathrm{L}} /$ pronounced in a carrier phrase, as described in section 2.5 below. The waveforms and spectrograms show consonant closure and release, and a portion of both preceding and following vowels (V1 and V2). An equal time period is shown for both allophones in each of the figures.

As is typical for Mee $/ \mathrm{g}^{\mathrm{L}} /$, the tokens presented here all have a relatively long and clearly identifiable closure phase. In this respect, Mee velar lateral is unlike that of Mid-Waghi, described and analyzed by Ladefoged et al. (1977). The release of Mee velar lateral is often heavily blended with the following vowel so that in many cases it was hard to separate release from V2. The patterns of closure and release duration vary across tokens, and do not seem to be dependent on the quality of the surrounding vowels. The tokens in Figure 1 and Figure 2 differ in release periodicity. For $\left[g^{\mathrm{L}}\right]$ the release was periodic in a majority of cases, thus Figure 1 (left panel) represents a more typical realization. On the other hand, for $\left[\mathrm{G}^{\mathrm{B}}\right]$ the release was often partially devoiced, thus both realizations were about equally common. Aperiodic release was often also accompanied by a partially devoiced $\left[\mathrm{G}^{\mathrm{B}}\right]$ closure, as seen in Figure 2, right panel. See also section 3.1 for our analysis of release periodicity.

Although this paper mainly focuses on $/ \mathrm{g}^{\mathrm{L}} /$ allophony, our elicitations reveal that other stops may also show variation in quality depending on the following vowel frontness. The voiceless $/ \mathrm{k} /$ is uvularized before back vowels, and it frequently lenites to a fricative $[\mathrm{x} / \chi]$ intervocalically. Two additional patterns were preliminarily noted in the speech of consultant $\mathrm{S} 2$ : the voiced coronal stop /d/ is sometimes produced with 
weak implosion phrase-initially, and the voiceless / $t /$ is sometimes affricated before front vowels. It remains to be seen how pervasive and regular these patterns of stop allophony are, we leave this issue for future research.

2.3 Participants and elicitation procedures Our data come from fieldwork with two speakers of Mee, to be referred to as S1 and S2. Our current data mostly come from S1, but the relevant aspects of $/ \mathrm{g}^{\mathrm{L}} /$ allophony were also checked with S2. Both our speakers are male, aged between 25 and 35. Both are bilingual in Mee and Indonesian, showing very good L2 command of German and some knowledge of English, and living in Germany at the time of elicitation. S1 speaks the Paniai dialect of Mee, which also shows some influence of the central Tigi dialect. S2 is a speaker of the Tigi dialect. Despite the dialectal differences in the lexicon of our speakers, the patterns of $/ g^{\mathrm{L}} /$ realization appear to be very similar, suggesting that $/ \mathrm{g}^{\mathrm{L}} /$ allophony may be present in multiple dialects of Mee.

Our main elicitations were carried out in a quiet room with continuous sound recording using Zoom H5 portable recorder. An AKG C-1000s microphone was used to record S1's main elicitations and Shure SM10A microphone was used to record S2's elicitations. Elicitations consisted of words an phrases, focusing on the basic sound contrasts of Mee, and specifically on the velar lateral. To confirm our impressions from elicitations, a controlled acoustic study of Mee $/ \mathrm{g}^{\mathrm{L}} /$ was conducted, as described in the following sections.

2.4 Acoustic study: predictions The acoustic study of Mee $/ \mathrm{g}^{\mathrm{L}} /$ was conducted with speaker S1. The acoustic distinctions between uvular and velar consonants are somewhat rarely addressed in the literature, although it is acknowledged that this contrast is particularly interesting since it might be hard to perceive (Shosted, 2011). Across languages, uvular and pharyngeal consonants are often associated with vowel lowering and backing (Bessell, 1998; Wilson, 2007; Shosted, 2011; Denzer-King, 2013). Thus Shosted (2011) compared the effects of velars and uvulars on a preceding vowel in the Mayan language Q'anjob'al, observing that uvulars tend to raise F1 and lower F2. Denzer-King (2013) finds that uvulars lower the F2 of the following /a/ in Tlingit (Na-Dene), compared to velars. The lowering and retraction effects of uvulars are also found for Nuu-chah-nulth (Wakashan) (Wilson, 2007) and for Interior Salish languages (Bessell, 1998), these two studies compare uvulars and pharyngeals to both velars and coronals.

The velar-uvular distinction manifests itself differently for preceding vs. following vowels, and for different vowel qualities. In Q'anjob'al the F2 effects of uvulars are more pronounced for front vowels [i e] (Shosted, 2011). Similarly, the results in Alwan (1986) suggest that in Arabic the uvular consonants lower F2 of a following front vowel /i:/ much more drastically than for /a: u:/ (see esp. pp. $70-78$ and Figure 3.10). Wilson (2007) reports varying degrees of lowering and backing for different vowels in Nuu-chah-nulth.

Based on these findings, we expect that compared to $\left[g^{\mathrm{L}}\right],\left[\mathrm{G}^{\mathrm{B}}\right]$ may have a backing and/or lowering effect on the preceding vowels. We also anticipate that these effects may be realized differently for different preceding vowel qualities.

In our impressionistic description, $\left[\mathrm{g}^{\mathrm{L}}\right]$ vs. $\left[\mathrm{G}^{\mathrm{B}}\right]$ also differ in release quality: lateral vs. fricative. ${ }^{2}$ Although we expect that the two $/ \mathrm{g}^{\mathrm{L}} /$ allophones will have different release spectra, we also anticipate that this prediction is hard to test in practice since $\left[\mathrm{g}^{\mathrm{L}}\right]$ and $\left[\mathrm{G}^{\mathrm{B}}\right]$ occur in different vocalic contexts. We preliminarily observed that the release of $\left[\mathrm{G}^{\mathrm{B}}\right]$ is subject to partial devoicing while devoicing almost never applies to $\left[\mathrm{g}^{\mathrm{L}}\right]$. We thus also predict a potential distinction in release periodicity for the two allophones.

2.5 Acoustic study: procedures Target words, described in section 2.6, were recorded in a carrier phrase given in (4).

$$
\begin{aligned}
& \text { Itoko_na-ti-dodou } \\
& \text { Now_n } 1 \mathrm{SG} \text {.O-say-POL.IMP } \\
& \text { Say_now }
\end{aligned}
$$

Carrier phrase recordings were made in a sound-attenuated booth at Leipzig University using Neumann TLM103 cardioid microphone and M-Audio Mobile Pre preamplifier. Stimuli sentences were presented in a random order on a computer screen. The experiment started with an instruction screen in German, asking the

2 See Mayes (1979) for an analysis of the release spectra in /k/ vs. /q/ in Thompson (Salishan). These results are not directly comparable to ours since in Mee we are dealing with velar laterals rather than plain stops. 
consultant to read the sentences as naturally as possible, and to repeat a sentence if a slip of tongue occurred. The consultant was also informed that some sentences may occur more than once. Three trial sentences preceded the main task, and a short break occurred in the middle of the experiment. The whole recording session lasted about forty minutes.

2.6 Acoustic study: stimuli Stimuli for the acoustic study with $\mathrm{S} 1$ consisted of words with $/ \mathrm{g}^{\mathrm{L}} / \mathrm{in}$ a diverse set of vocalic contexts. Our words were minimally bisyllabic, and were not controlled for tone, syllable structure, or morphological complexity - controlling these factors appeared impractical given the lack of tonal annotation and the overall relatively small size of our main dictionary source (Steltenpool, 1969). Three tokens were excluded from acoustic measurements since extraneous noise was present or the realization of $/ \mathrm{g}^{\mathrm{L}} /$ was clearly deviant (see section 2.7 ).

Our final token set contained about the same number of $/ \mathrm{g}^{\mathrm{L}} /$ before front vowels (158 tokens of 52 words) and $/ \mathrm{g}^{\mathrm{L}} /$ before back vowels (154 tokens of 45 words). In designing the word sets we attempted to include at least three distinct words with $/ g^{\mathrm{L}} /$ in each V_V context. Since Mee has three back vowel qualities /a o u/ and two front $/ \mathrm{i}$ e/, this also meant that we included more distinct words with $/ \mathrm{g}^{\mathrm{L}} /$ before front vowels.

In some of the vocalic environments we could not identify enough words that would be familiar to our consultant. This problem was particularly pronounced for $/ \mathrm{u} /$, which is the least frequent vowel of Mee. To balance our stimulus set, we included more repetitions of the available words in those cases.

The table in (5) presents the number of distinct words (types) with $/ \mathrm{g}^{\mathrm{L}} /$ in each environment in our stimuli set. The table (6) presents the number of individual tokens/repetitions.

Stimuli words by environment

\begin{tabular}{l|llllllllll} 
& $\mathrm{a}$ & $\mathrm{e}$ & $\mathrm{e}$ & $\mathrm{ei}$ & $\mathrm{eu}$ & $\mathrm{i}$ & i: & o & ou & $\mathrm{u}$ \\
\hline$\#$ & 3 & 3 & 0 & 2 & 0 & 3 & 0 & 3 & 0 & 2 \\
$\mathrm{a}$ & 3 & 3 & 1 & 1 & 0 & 6 & 1 & 3 & 0 & 2 \\
$\mathrm{e}$ & 3 & 3 & 2 & 0 & 0 & 3 & 0 & 3 & 0 & 3 \\
$\mathrm{i}$ & 3 & 0 & 3 & 1 & 1 & 3 & 0 & 2 & 1 & 0 \\
$\mathrm{o}$ & 3 & 3 & 0 & 1 & 0 & 4 & 0 & 3 & 0 & 1 \\
$\mathrm{u}$ & 3 & 0 & 2 & 1 & 0 & 2 & 3 & 0 & 1 & 3
\end{tabular}

(6) Stimuli tokens by environment

\begin{tabular}{l|llllllllll} 
& a & e & e: & ei & eu & i & i: & o & ou & u \\
\hline$\#$ & 9 & 9 & 0 & 6 & 0 & 9 & 0 & 9 & 0 & 9 \\
a & 9 & 8 & 3 & 3 & 0 & 18 & 3 & 9 & 0 & 9 \\
e & 9 & 9 & 6 & 0 & 0 & 9 & 0 & 9 & 0 & 9 \\
i & 9 & 0 & 9 & 3 & 3 & 9 & 0 & 9 & 3 & 0 \\
o & 9 & 9 & 0 & 3 & 0 & 12 & 0 & 8 & 0 & 9 \\
u & 9 & 0 & 9 & 3 & 0 & 6 & 9 & 0 & 9 & 8
\end{tabular}

In the i_u environment, only a few words could be found in the dictionary (Steltenpool, 1969), and none of these words were familiar to our consultant. For all other environments, we recorded at least nine tokens of $/ \mathrm{g} /$. The total number of target word tokens we analyzed was 313 .

The 313 stimuli tokens were randomly interspersed with 300 filler tokens. Our fillers were 100 disyllabic or longer frequent Mee words identified in our elicitations, each filler word was repeated three times to yield 300 tokens. As with the target words, some of our fillers were morphologically complex. None of the fillers contained the sound $/ \mathrm{g}^{\mathrm{L}}$.

2.7 Annotation The target tokens containing $/ \mathrm{g}^{\mathrm{L}} /$ were extracted from main recordings and annotated for acoustic analysis in Praat (Boersma \& Weenink, 2017). Within each recording, we attempted to single out the following intervals: the vowel before $/ g^{\mathrm{L}} /\left(\mathrm{V} 1\right.$, if present), closure, and the release plus vowel after $/ \mathrm{g}^{\mathrm{L}} /$ (RV2). Where possible, we attempted to also separate release (R) from V2, but this was possible for only about a third of our tokens.

Although V1 and V2 intervals were annotated in all cases, the duration of V1 and V2 will not be analyzed since the preceding and following context is not controlled for. Two tokens (the sixth repetition of [wiG $\left.{ }^{\mathrm{B}} \mathrm{orta}\right]$ 'be torn' and the second repetition of [akawag $\left.{ }^{\mathrm{L}} \mathrm{e}\right]$ 'they fight each other') were excluded from annotation due to an apparent non-speech noise during $/ \mathrm{g}^{\mathrm{L}} /$ production: presumably the speaker's lips got too close to the microphone.

V1 was annotated from the onset of periodic signal (after voiceless sounds or a pause) or from the abrupt rise of energy in higher frequencies until the abrupt lowering of energy in higher frequencies. The closure interval was usually characterized by very low amounts of energy in higher frequencies. In a few cases the closure contained low-intensity aperiodic noise in higher frequencies, consistent with $/ \mathrm{g}^{\mathrm{L}} /$ being lenited to a more fricative-like quality. Word-initial $/ \mathrm{g}^{\mathrm{L}} /$ sometimes showed evidence of glottalization in the closure phase. One token of $/ \mathrm{g}^{\mathrm{L}} /$ (third repetition of [buG ${ }^{\mathrm{B}} \mathrm{uwa}$ ] 'forest') was excluded due to an extremely high 
degree of lenition where the closure appeared as a sonorant, hard to separate from the surrounding vowel intervals.

We annotated a separate release only in 111 tokens out of 312 , i.e. about $35 \%$. We defined the release as an interval that either lacked periodic signal or had clearly attenuated formant structure in higher frequencies.

The V2 interval was annotated from the abrupt rise of energy in higher frequencies until the end of periodic signal or until the lowering of energy in higher frequencies. In a few cases V2 was followed by a glide, and we set the boundary roughly in the middle of the format transitions interval for those. This latter choice did not influence our results since we did not analyze V2 duration.

\section{Results: velar lateral realization}

3.1 Release quality The two allophones of Mee posterior affricate have different release qualities: the difference was salient to us, and the consultants also showed some awareness of this difference. While $\left[\mathrm{G}^{\mathrm{B}}\right]$ release sounds to us as a uvular fricative, which is sometimes partially devoiced, the release of $\left[g^{\mathrm{L}}\right]$ sounds as a lateral sonorant. This difference manifests itself in the spectral properties and periodicity of the release.

We expect that the release of $\left[\mathrm{G}^{\mathrm{B}}\right]$ is less periodic than $\left[\mathrm{g}^{\mathrm{L}}\right]$ release since it is fricated and sometimes partially devoiced. To assess release periodicity, we measured harmonics to noise (HtoN) ratio within $20 \mathrm{~ms}$ of the closure offset. $\left[\mathrm{g}^{\mathrm{L}}\right]$ showed more periodic release with a mean HtoN ratio of $7.08 \mathrm{~dB}$ (s.d. 2.74) vs. $5.47 \mathrm{~dB}$ (s.d. 3.3) for $\left[\mathrm{G}^{\mathrm{B}}\right]$. Since $\mathrm{HtoN}$ ratio is a logarithmic measure, the small difference in the mean corresponds to a relatively large perceptual distinction. The difference in HtoN ratio between two $/ \mathrm{g}^{\mathrm{L}} /$ allophones was significant, based on a linear mixed effects model with V2 frontness as a fixed effect; item and repetition number as random effects $(\beta=1.75 ; S E=0.45 ; p<0.001)$. This result is compatible with $\left[\mathrm{G}^{\mathrm{B}}\right]$ release being less sonorous and more subject to devoicing.

A preliminary visual examination of release spectra revealed a very high degree of variability for both allophones. The release did not always have identifiable formants, and in many cases the release was heavily blended with a following vowel. The duration of the release was also highly variable. Given this high variability, it seems hard to find an objective acoustic spectral measure that would meaningfully apply to all cases. We measured centre of gravity $(\mathrm{CoG})$ for the tokens where release could be separated from $\mathrm{V} 2(\mathrm{~N}=$ 111), and the results were as follows: mean $\mathrm{CoG} 3167 \mathrm{~Hz}$ (s.d. 1088) for $\left[g^{\mathrm{L}}\right]$ vs. mean $2139 \mathrm{~Hz}$ (s.d. 1175) for $\left[\mathrm{G}^{\mathrm{B}}\right]$.

$\left[\mathrm{G}^{\mathrm{B}}\right]$ release has a lower $\mathrm{CoG}$ than $\left[\mathrm{g}^{\mathrm{L}}\right]$ release and this spectral measure is highly variable, as witnessed by high standard deviations. Despite high variability, the difference in CoG is significant, as revealed by a linear mixed effects regression model with $\mathrm{V} 2$ frontness as a fixed effect and item and repetition number as random effects ( $\beta=1126, S E=281, p<0.001)$. However, the results on release CoG should be interpreted with caution for two reasons. First, $\mathrm{CoG}$ is a very coarse spectral measure. Second, the release spectra are likely to be influenced by the spectral properties of the following vowels, and the front vowels after $\left[\mathrm{g}^{\mathrm{L}}\right]$ will have a higher $\mathrm{F} 2$ than the back vowels after $\left[\mathrm{G}^{\mathrm{B}}\right]$. Relatedly, the acoustic cues to the release difference likely reside not only in the release interval, but also in the quality of the following vowel. However, any analysis of the quality of $\mathrm{V} 2$ is challenged by the fact that the $\mathrm{V} 2$ contexts are different for the two allophones. $\left[\mathrm{G}^{\mathrm{B}}\right]$ occurs only before back vowels while $\left[g^{\mathrm{L}}\right]$ occurs only before front vowels - hence the two contexts are not directly comparable.

To summarize, the two allophones of Mee velar lateral differ in the release quality. We describe the release of $\left[\mathrm{g}^{\mathrm{L}}\right]$ as a sonorant which is periodic in the majority of cases whereas the release of $\left[\mathrm{G}^{\mathrm{B}}\right]$ is a fricative. Acoustically, $\left[\mathrm{G}^{\mathrm{B}}\right]$ release is less often periodic, and it has a lower Centre of Gravity.

3.2 V1 formants and transitions For the vowel preceding $/ \mathrm{g}^{\mathrm{L}} /(\mathrm{V} 1)$, formants were measured at five timepoints during the vowel ranging in equal intervals from $10 \%$ to $90 \%$ of the vowel duration. Formant measurements were taken automatically in Praat, using linear interpolation Burg LPC with a time step of $10 \mathrm{~ms}$ and window length of $25 \mathrm{~ms}$. Figure 3 shows formant tracks for F1-F3 in the vowel preceding $/ \mathrm{g}^{\mathrm{L}} /$ The left context of each vowel is not controlled in our dataset, hence the formant values closer to the vowel beginning are more highly variable.

It can be observed that a following uvular $\left[\mathrm{G}^{\mathrm{B}}\right]$ has a more consistent and a more pronounced effect of lowering F2 for each vowel whereas a following velar $\left[g^{\mathrm{L}}\right]$ shows F2 lowering only for $/ \mathrm{u}$ o/. The difference in F2 effects between $\left[\mathrm{G}^{\mathrm{B}}\right]$ and $\left[\mathrm{g}^{\mathrm{L}}\right]$ appears to be the most pronounced for $/ \mathrm{i}$ e a/ - this result is similar to 

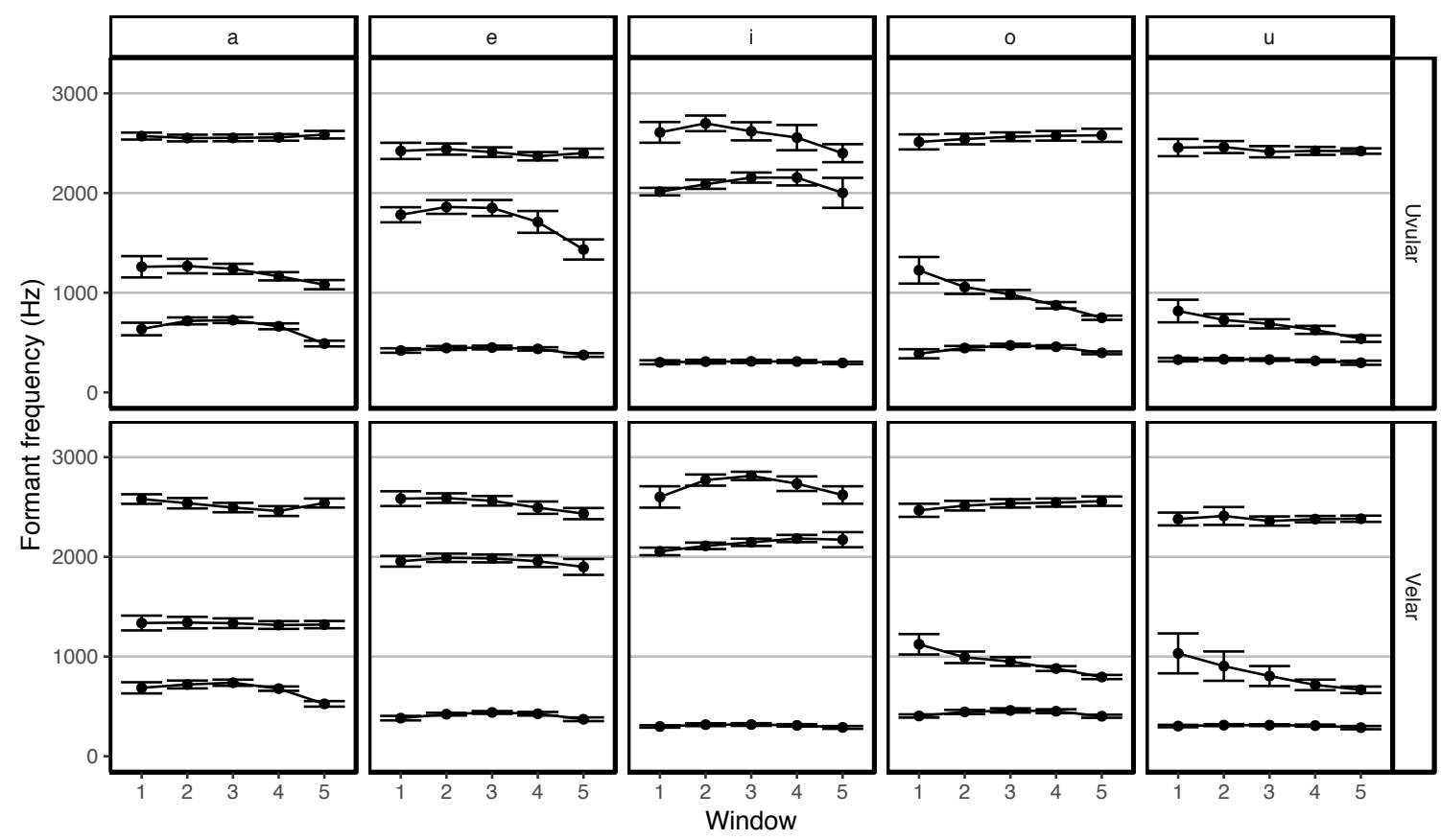

Figure 3: Average formant tracks for vowels preceding $/ \mathrm{g}^{\mathrm{L}} /$. Error bars show $95 \%$ confidence intervals.

Shosted (2011: Figure IV-4). F2 lowering next to $\left[\mathrm{G}^{\mathrm{B}}\right]$ initiates at least around the midpoint of the vowel and continues towards the last timepoint. Interestingly, the F1 tracks do not seem to show a robust difference in velar vs. uvular context. Thus while Mee uvular $\left[\mathrm{G}^{\mathrm{B}}\right]$ has a backing effect on preceding vowels, Figure 3 shows no obvious lowering effect.

The effects of the following consonant are expected to be observed most robustly towards the end of the vowel. The transitional values for each vowel, taken at $90 \%$ duration, are plotted in Figure 4. To correct for possible inaccuracies in automated formant analysis we excluded the formant outliers for this plot, and for the statistical analysis reported below. Vowels that fall outside the $95 \%$ confidence interval within the F1xF2 space were considered outliers. Two tokens of /u/ were excluded from formant measurements (first repetitions of [ $\left.\mathrm{bug}^{\mathrm{L}} \mathrm{L}\right]$ ' $g a r d e n '$ ' and $\left[\mathrm{kuG}^{\mathrm{B}} \mathrm{a}\right]$ 'there, in that direction') since in both cases F1 and F2 nearly merged making it hard to track the formants automatically.

As seen in Figure 4, at the 90\% timepoint all vowels, perhaps with the exception of /o/, show a clear separation between the formant transitions into $\left[\mathrm{g}^{\mathrm{L}}\right]$ and the formant transitions into $\left[\mathrm{G}^{\mathrm{B}}\right]$. This distinction is based primarily on F2 rather than F1, consistent with the trend already observed in Figure 3.

We analyzed F2 transitions at $90 \%$ of V1 duration with a linear mixed effects regression model taking V1 quality and consonant place (velar vs. uvular) as fixed effects and including item and repetition number as random effects. The significant effect of consonant place $(\beta=220 ; S E=60 ; p<0.001)$ confirms that the $\left[\mathrm{G}^{\mathrm{B}}\right]$ allophone is realized with a closure that is further back than that of $\left[\mathrm{g}^{\mathrm{L}}\right]$. An expected significant effect of V1 quality was also found for all vowels.

The interaction between V1 being [e] and consonant place was significant $(\beta=246 ; S E=87 ; p<$ 0.01 ), and the interaction between V1 being [o] and consonant place was marginal $(\beta=-175 ; S E=$ $90 ; p=0.055)$. These interactions are also seen in Figure 4 where the F2 values for /e/ are very clearly distinct between the two contexts, while the F2 values for /o/ are hardly separable. These results are consistent with the literature suggesting that uvular effects on different vowels are distinct, and that the front vowels tend to be affected the most (see section 2.4 for discussion).

Based on Figures 3-4, posterior affricate allophony does not seem to have a consistent effect on the first formant of preceding vowels. We analyzed $\mathrm{F} 1$ transitions into $/ \mathrm{g}^{\mathrm{L}} /$ at $90 \%$ of $\mathrm{V} 1$ duration with a linear regression model taking V1 quality and consonant place (velar vs. uvular) as fixed effects and including item and repetition number as random effects. The model showed an expected significant effect of V1 quality, but 


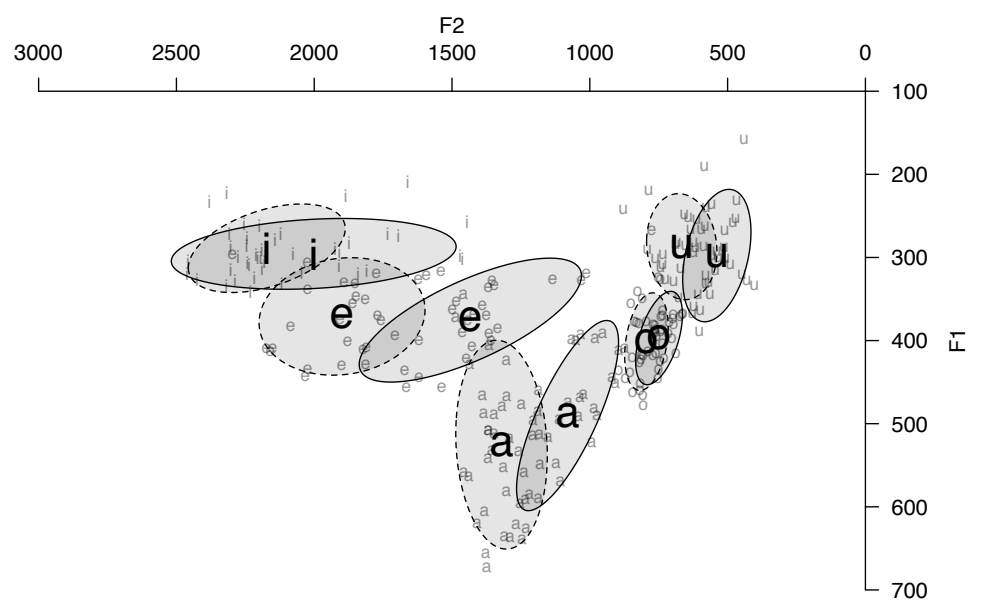

Figure 4: Formant transitions from $\mathrm{V} 1$ into $\left[\mathrm{g}^{\mathrm{L}}\right]$ (dotted line) and $\left[\mathrm{G}^{\mathrm{E}}\right]$ (solid line).

the effect of consonant place was not significant $(\beta=29.4 ; S E=21.2 ; p=0.17)$. Thus we do not find numeric evidence of vowel lowering before $/ \mathrm{G}^{\mathrm{E}} /$.

To summarize, our analysis of V1 formants and transitions into $/ \mathrm{g}^{\mathrm{L}} /$ revealed that the uvular allophone had a backing effect on the preceding vowel. At the same time, our data show no evidence of a lowering effect. Overall however, and especially taken together with the difference in release quality, these results align with our description of $/ g^{\mathrm{L}} /$ allophony.

3.3 Summary We have investigated the realization of Mee velar lateral based on elicitations with two speakers and on a controlled acoustic study with one of the speakers. Our main finding is that Mee posterior affricate is realized as a velar $\left[g^{\mathrm{L}}\right]$ before front vowels but uvular $\left[\mathrm{G}^{\mathrm{B}}\right]$ before back vowels. Our acoustic study demonstrated a distinction in release spectra between the two allophones, and a distinction in release periodicity: on average the release was less periodic before back vowels than before front vowels. Our release measurements are consistent with the release target being a fricative rather than a sonorant for $\left[\mathrm{G}^{\mathrm{B}}\right]$ and with a higher likelihood of partial devoicing for $\left[\mathrm{G}^{\mathrm{B}}\right]$ release.

We also demonstrated that $\mathrm{F} 2$ of the preceding vowel is higher before $\left[\mathrm{g}^{\mathrm{L}}\right]$ and lower before $\left[\mathrm{G}^{\mathrm{B}}\right]$, and this is compatible with a difference in constriction location for consonant closure, as well as with reports of vowel retraction next to uvulars in other languages (Bessell, 1998; Wilson, 2007; Shosted, 2011). The F2 effects are pronounced to a different extent for different vowels: [e] is the most distinct and [o] is the least distinct in our dataset. This individual variability is, again, consistent with the results on other languages.

Interestingly, we did not find support for a significant lowering effect on the vowel before $\left[\mathrm{G}^{\mathrm{B}}\right]$ : the $\mathrm{F} 1$ of the vowels before different velar lateral allophones was not significantly distinct. A number of existing phonetic studies of vowels next to uvulars show either just lowering or just backing for some vowels or for some contexts (Alwan, 1986; Wilson, 2007). It is interesting to observe that in Mee, vowel backness is affected by uvulars more robustly than vowel height. This finding contributes to our understanding of how uvulars and velars are distinguished perceptually across languages (cf. Shosted 2011).

Although none of our acoustic measurements pertain to the closure interval itself, the two allophones differ in both release and V1 formant transitions. We therefore infer that the constriction location for the closure is likely also distinct. Thus Mee velar lateral allophony affects both the closure and the release of the consonant. This is somewhat unusual for consonant-vowel place feature interactions. In fact Ní Chiosáin \& Padgett (1993) propose that consonants and vowels never interact in major place, or C-Place features in their geometry. In their theory, $\mathrm{C}-\mathrm{V}$ interactions only affect the V-Place features which describe the secondary articulation of consonants. Our analysis in the following section suggests a refinement to this generalization. Although there are still no direct $\mathrm{C}-\mathrm{V}$ interactions in major place, two local interactions may conspire to yield a similar effect. 


\section{Analysis}

In the following, we will sketch an Optimality Theory analysis of the posterior affricate allophony in Mee. Our analysis incorporates three main ideas. First, we assume that the interaction between vowel backness and the velar-uvular distinction of the stop closure is indirect and mediated by the effects of the vowel on consonant release. While we still assume no constraints that require $\mathrm{C}-\mathrm{V}$ agreement in major place, there are two kinds of local AGREE-constraints (schematized in (7)): AGREE ${ }_{\text {Rel-v }}^{[\mathrm{F}]}$ demanding a consonantal release and a following vowel to agree in some feature $F$ and AGREE $_{\mathrm{Clo}-\mathrm{Rel}}^{[\mathrm{F}]}$ requiring closure and release to agree in place. In some ways our analysis is analogous to the notion of rule telescoping that refers to a situation where the combination of two natural rules yields an unnatural rule when there is no evidence anymore for the intermediate representation (Kenstowicz \& Kisseberth, 1977). Similarly in our analysis two separate local agreement constraints derive the apparent more general effect of $\mathrm{C}-\mathrm{V}$ interaction. On this analogy, our analysis can be labeled constraint telescoping.

(7) Schematic representaion of agreement between consonant closure and vowel via release

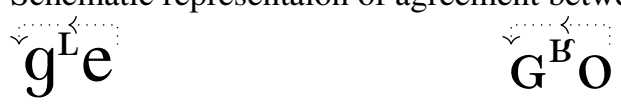

Second, as anticipated in section 2.2, we assume that the posterior affricate is underlyingly specified as a complex segment with a lateral release: $/ g^{\mathrm{L}} /$ (though see some remarks on Richness of the Base below). Our account rests on the assumption that complex segments have two distinct phases (closure and release), and that each phase can be associated with its own features - the precise implementation of these assumptions is irrelevant to our purposes, see e.g. the X-slots in Clements \& Hume (1995), the Aperture Theory (Steriade, 1993), and Q-Theory (Shih \& Inkelas, 2019).

Finally, building on Becker (2016) and Svantesson et al. (2005), we assume that the difference between uvulars and velar consonants in Mee is due to a feature shared between consonants and vowels - [back] in our case. The idea that posterior consonants may have vocalic features goes back to Chomsky \& Halle (1968). Apart from the AGREE constraints, formalized in (8), we need an additional constraint on the release quality. Uvular laterals are not attested in the worlds languages (Ladefoged et al., 1977; Ladefoged \& Maddieson, 1996), and we assume a high ranked constraint against uvular lateral release.

(8) Constraints enforcing agreement for backness

a. AGREE ${ }_{\text {Rel-V }}^{[\text {back }}$

Count one violation for every sequence of adjacent consonant release and vowel that do not agree in their [back] feature value.

b. AGREE $E_{\text {Clo-Rel }}^{\text {back] }}$

Count one violation for every sequence of adjacent consonant closure and release that do not agree in their [back] feature value.

c. ${ }^{*} \underline{L}$

Count on violation for every segment that is uvular (=[Dorsal,-back $])$ and lateral.

Several faithfulness constraints are needed to ensure that we change the consonant instead of changing the vowel. ${ }^{3}$ We propose that since vowels are more prominent, feature preservation in vowels is regulated by a special family of IDENT constraints, specific to vowels, as in (9). In Mee, the IDENT constraint for the feature [back] restricted to vowels has to be ranked higher than the more general version of the constraint. This forces the direction of the assimilation to go from vowel to consonant only. For other IDENT constraints involved, appealing to just the general version suffices for our purposes.

Faithfulness constraints

a. IDENT(back $)_{\mathrm{V}}$

Count one violation for every change of the feature [back] in a vowel.

3 In addition, some general faithfulness constraint like MAX is assumed to be high-ranking, in order to ensure that the underlying posterior affricate does not lose its release altogether. A similar result can be achieved by postulating a constraint against unreleased prevocalic consonants. 

b. IDENT(back)
Count one violation for every change of the feature [back].
c. IDENT(sonorant)
Count one violation for every change of the feature [sonorant].

Although we think there may be reasons to believe that $/ \mathrm{g}^{\mathrm{L}} /$ is the lexical shape of Mee posterior affricate, our analysis needs to handle some additional details. Since OT commits to Richness of the Base, we need to show that both underlying $/ \mathrm{g}^{\mathrm{L}} /$ and underlying $/ \mathrm{G}^{\mathrm{B}} /$ would merge to be pronounced as the actual output forms, regardless of the input. To show that this is achieved, we will analyze the input that has an opposite release specification from the output in each case: before back vowels even a consonant with the release specified [+continuant; +sonorant; -nasal; - back] would surface as $\left[\mathrm{G}^{\mathrm{B}}\right]$ whereas before front vowels a consonant with the release specified [+continuant; -sonorant; -nasal; +back] would surface as $\left[\mathrm{g}^{\mathrm{L}}\right]$.

Putting these assumptions together, we arrive at the evaluation presented in (10). In the underlying form $/ \mathrm{eg}^{\mathrm{L}} \mathrm{ou} /$ the voiced dorsal affricate is followed by a back vowel. Simply preserving the lateral release, as in candidate (a), is not enough to satisfy the AGREE constraints, since the velar lateral release is [-back] but the following vowel /ou/ is [+back]. This would be a violation of the $\mathrm{AGREE}_{\mathrm{Rel-V}}^{[\mathrm{back}]}$ constraint. Only assimilating the release to the [+back] feature of the vowel, as in candidate (b), will violate the AGREE $\mathrm{E}_{\mathrm{Clo}-\mathrm{Rel}}^{\text {[back }}$ constraint that demands closure and release to agree in place features. Therefore candidate (c) that assimilates both closure and release to the backness value of the vowel becomes optimal, even though this means changing two features of the release ([back] and [sonorant]) and changing the [back] features of the consonant closure. Candidate (e) has a uvular lateral release, and thus violates the high ranked constraint against uvular laterals. Similarly, assimilating the vowel to the consonant closure, as in candidate (d), violates the high ranked constraint $\operatorname{ID}(b)_{V}$.

\begin{tabular}{|c||c:c|c:c|c:c|}
\hline$/ \mathrm{eg}^{\mathrm{L}} \mathrm{Ou} /$ & $\underline{\mathrm{L}}$ & $\mathrm{ID}(\mathrm{BK})_{\mathrm{V}}$ & $\mathrm{AGR}_{\mathrm{Rel-V}}^{[b]}$ & $\mathrm{AGR}_{\mathrm{Clo}-\mathrm{Rel}}^{[b]}$ & $\mathrm{ID}(\mathrm{BK})$ & $\mathrm{ID}(\mathrm{SON})$ \\
\hline a. $\mathrm{eg}^{\mathrm{L}} \mathrm{Ou}$ & & & $* !$ & & & \\
\hline b. $\mathrm{eg}^{\mathrm{G}} \mathrm{Ou}$ & & & & $* !$ & $*$ & $*$ \\
\hline c. $\mathrm{eG}^{\mathrm{B}} \mathrm{Ou}$ & & & & & $*$ & $*$ \\
\hline d. $\mathrm{eg}^{\mathrm{L}} \mathrm{ei}$ & & $* !$ & & & & \\
\hline e. $\mathrm{eG} \mathrm{e}^{\mathrm{L}} \mathrm{Ou}$ & $* !$ & & & & $*$ & \\
\hline
\end{tabular}

The evaluation of $/ \mathrm{G}^{\mathrm{B}} /$ before a front vowel is illustrated in (11). Candidates (b) and (c) again are out because the agreement constraints are not satisfied. Assimilating the vowel to the consonant as shown in candidate (e) would again violate the constraint IDENT(back) $)_{V}$ against changing the backness value vowels.

\begin{tabular}{|c|c|c|c|c|}
\hline$/ \mathrm{juG}^{\mathrm{B}} \mathrm{ei} /$ & $\begin{array}{l:l}{ }^{*} \underline{\mathrm{L}} & \mathrm{ID}(\mathrm{BK})_{\mathrm{V}} \\
\end{array}$ & 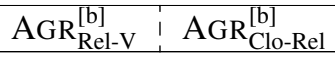 & $\operatorname{ID}(\mathrm{BK})$ & ID(SON) \\
\hline 囎 a. jug ${ }^{\mathrm{L}} \mathrm{ei}$ & 1 & 1 & * & * \\
\hline b. jug $^{\mathrm{B}} \mathrm{ei}$ & 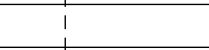 & $* !$ & & \\
\hline c. juG ${ }^{\mathrm{L}} \mathrm{ei}$ & 1 & $* !$ & * & $*$ \\
\hline d. jug ${ }^{\mathrm{B}} \mathrm{Ou}$ & $* !$ & 1 & & \\
\hline
\end{tabular}

In this tableau, we do not consider one candidate that nevertheless could be a potential winner, namely * [jug $\left.{ }^{\mathrm{Y}} \mathrm{ei}\right]$. This would be the pronunciation of an affricate with release specified [+continuant; -sonorant; -nasal; -back]. The attestation of such affricates is dubious, but the fact that such a sound does not arise in Mee presents a larger question. In particular, there must be some constraint that would force the release to be lateral (i.e. [+sonorant] in our terms), rather than simply a fricative before front vowels. This constraint could probably be related to the diachronic phonetic sources of lateral release, but at this point we do not understand the phonetic history of velar laterals well enough. Thus we leave the investigation of why lateral releases are lateral (rather than just fricative) for the future, hoping that more phonetic data on velar laterals could shed light on this issue. See also the discussion of a similar, though not identical, puzzle in Hiw from a historical perspective in François (2010: 421 - 422).

To summarize, the analysis developed in this section is based on two basic premises. First, agreement constraints require closure, release and the following vowels to have the same value for the feature [back]. Two local constraints achieve a long distance effect here by what we call constraint telescoping. Second, 
the posterior affricate in Mee is specified underlyingly as a complex segment with different features for closure and release phase. Thus synchronically the consonant must be specified as an affricate of some sort underlyingly, and the agreement constraints place tight restrictions on the quality of its release.

\section{Conclusion}

We have presented phonetic and fieldwork data documenting allophony of the posterior affricate in Mee. This affricate is realized as $\left[\mathrm{g}^{\mathrm{L}}\right]$ before front vowels $\left[\mathrm{i}\right.$ e] and corresponding diphthongs but as $\left[\mathrm{G}^{\mathrm{B}}\right]$ before back vowels $[\mathrm{a} \mathrm{o} \mathrm{u}]$ and diphthongs. To our knowledge, this is the first report of this allophony pattern, and the sound $\left[\mathrm{G}^{\mathrm{B}}\right]$ so far has only been reported as marginal in Xumi (Chirkova \& Chen, 2013).

Phonologically speaking, we have argued that the Mee velar lateral is best analyzed as an underlying affricate. On the one hand it patterns with [-continuant] segments in a number of ways, but on the other hand its release quality cannot be fully derived from the context.

The Mee allophonic alternation is interesting because the following vowel has an effect on place of articulation in both the release and the closure of the consonant. The Mee example thus presents a challenge to the idea that consonant-vowel place feature interactions only affect V-Place or similar features which are responsible for secondary articulation usually manifested in the release (Ní Chiosáin \& Padgett, 1993; Padgett, 2011). We argue that the Mee pattern arises from the activity of two kinds of AGREE constraints: constraints enforcing vowel effects on the release, and constraints that require feature agreement between closure and the release. Thus although the consonant's major place is not directly affected by the vowel, it can still depend on vowel quality due to a sort of constraint telescoping effect.

Our analysis predicts similar effects on Mee $/ \mathrm{k} /$ which is realized as a stop in most cases. Although our preliminary observations do suggest that the quality of $/ \mathrm{k} /$ also varies between velar and uvular based on vowel frontness, we leave a more detailed investigation for future research.

\section{References}

Alwan, Abeer (1986). Acoustic and perceptual correlates of pharyngeal and uvular consonants. Master's thesis, MIT.

Becker, Laura (2016). Long-distance relations in Uyghur: Harmony between vowels, between consonants, and across. Ms., Leipzig University.

Bessell, Nicola J. (1998). Local and non-local consonant-vowel interaction in Interior Salish. Phonology 15.1, 1-40.

Blevins, Juliette (1994). A place for lateral in the feature geometry. Journal of Linguistics 30, 301 - 348.

Boersma, Paul \& David Weenink (2017). Praat: Doing phonetics by computer. Software.

Chirkova, Katia \& Yiya Chen (2013). Xumi (part 1): Lower Xumi, the variety of the lower Shuiluo river. JIPA 43:3.

Chomsky, Noam \& Moris Halle (1968). The Sound Pattern of English. Harper and Row, New York.

Clements, Nick \& Elizabeth Hume (1995). The internal organization of speech sounds. Goldsmith, John A. (ed.), The Handbook of Phonological Theory, Blackwell, Cambridge and Oxford, 245-306.

Denzer-King, Ryan (2013). The acoustics of uvulars in Tlingit. Master's thesis, Rutgers University.

Doble, Marion (1962). Essays on Kapauku grammar. Nieuw-Guinea Studiën 6, 152-155, 211-218, 279-298.

Doble, Marion (1987). A description of some features of Ekari language structure. Oceanic Linguistics 26:1-2, 55-113.

François, Alexandre (2010). Phonotactics and the prestopped velar lateral of Hiw: resolving the ambiguity of a complex segment. Phonology 27, 393-434.

François, Alexandre (2011). Where *R they all? The geography and history of *R-loss in Southern Oceanic languages. Oceanic Linguistics 50:1, 140-197.

Hyman, Larry \& Niko Kobepa (2013). On the analysis of tone in Mee (Ekari, Ekagi, Kapauku). Oceanic Linguistics 52:2, 307-317.

Kenstowicz, Michael \& Charles Kisseberth (1977). Topics in phonological theory. Academic Press, New York.

Ladefoged, Peter \& Ian Maddieson (1996). The Sounds of the World's Languages: 2nd Edition. Blackwell Publishers, Oxford.

Ladefoged, Peter, Ann Cochran \& Sandra Disner (1977). Laterals and trills. JIPA 7:2, 46-54.

Larson, Gordon \& Mildred Larson (1958). Preliminary studies in the Moni language. Bijdragen tot de Taal-, Land -en Volkenkunde 114:4, 406 - 431.

Larson, Gordon P. \& Mildred O. Larson (1972). The Ekagi-Wodani-Moni language family of West Irian. Irian 1:3, 80-95.

Mayes, Sharon V. (1979). An acoustic analysis of Thompson velar/k/ and uvular /q/. University of Hawaii Working Papers in Linguistics 11, $11-22$.

Moxness, Michael (2011). Morphosyntactic correlates of reference in Auye. Linguistic form and narrative role in a Papuan language. SIL Electronic Working Papers 2011:3.

Ní Chiosáin, Máire \& Jaye Padgett (1993). Inherent VPlace. Ms. University of Dublin and University of California, Santa Cruz. 
Padgett, Jaye (2011). Consonant-vowel place feature interactions. Van Oostendorp, Marc, Colin Ewen, Elizabeth Hume \& Keren Rice (eds.), The Blackwell Companion to Phonology, Blackwell, vol. 3.

Shih, Stephanie S \& Sharon Inkelas (2019). Autosegmental aims in surface optimizing phonology. Linguistic Inquiry .

Shosted, Ryan (2011). Towards a glottalic theory of Mayan. Avelino, Heriberto (ed.), New Perspectives in Mayan Linguistics, Cambridge Scholars Publishing, Newcastle, 80 - 113.

Steed, William \& Peter Hardie (2004). Acoustic properties of the Kuman voiceless velar lateral fricative. Bow, Catherine (ed.), Proceedings of the 10th Australasian International Conference on Speech Science and Technology, Australian Speech Science and Technology Association, Sydney, 346 - 351.

Steltenpool, J. (1969). Ekagi-Dutch-English-Indonesian Dictionary, vol. 56 of Verhandelingen van het KITLV. Martinus Nijhoff, The Hague.

Steriade, Donca (1993). Closure, release, and other nasal contours. Huffman, Marie K. \& Rena A. Krakow (eds.), Nasals, nasalization, and the velum, Academic Press, San Diego, 401-470.

Svantesson, Jan-Olof, Anna Tsendina, Anastasia Karlsson \& Vivan Franzen (2005). The Phonology of Mongolian. Oxford University Press, Oxford.

Tebay, Sören (2018a). Linear order in Mee vowel coalescence. Ms, Leipzig University.

Tebay, Sören (2018b). Towards a reconstruction of Proto-Paniai Lakes. Ms., Leipzig Universtiy.

Wilson, Ian (2007). The effects of post-velar consonants on vowels in Nuu-chah-nulth: Auditory, acoustic, and articulatory evidence. The Canadian Journal of Linguistics 52:1/2, 43 - 70.

Worbs, Sören (2016). Positionally restricted tone systems in Papuan languages. BA thesis. Leipzig University. 